\title{
Quality of Life Among Girls with or Without Clinically Significant Premenstrual Syndrome
}

\author{
Wafaa Taha Ibrahim Elgzar ${ }^{1, \text { *, Samiha Hamdi Sayed }}{ }^{2}$ \\ ${ }^{1}$ Obstetrics and Gynaecologic Nursing, Damanhur University, Damanhur, Egypt \\ ${ }^{2}$ Community Health Nursing, Damanhur University, Damanhur, Egypt
}

Email address:

Wafaa22006@yahoo.com (W. T. I. Elgzar)

${ }^{*}$ Corresponding author

\section{To cite this article:}

Wafaa Taha Ibrahim Elgzar, Samiha Hamdi Sayed. Quality of Life Among Girls with or Without Clinically Significant Premenstrual Syndrome. American Journal of Nursing Science. Vol. 6, No. 2, 2017, pp. 87-98. doi: 10.11648/j.ajns.20170602.13

Received: December 29, 2016; Accepted: January 10, 2017; Published: February 16, 2017

\begin{abstract}
Premenstrual syndrome (PMS) is one of the most vague and ill-defined phenomena in the field of woman health. Almost all its definitions concluded that it is a cyclic recurrence of distressing physical, psychological and behavioral symptoms, that occur during the luteal phase of menstrual cycle and evaporates within two days of the onset of menses. PMS may range in its severity from mild ( $90 \%$ of females) to moderate or severe (12.6-31\% of females). The last type is called Clinically Significant Premenstrual Syndrome (CSPMS). The emergence of CSPMS during the teen years complicates the process of puberty and assumed to have negative impact on the girl's Health Related Quality of Life (HRQOL). This study aimed to compare HRQOL in the girls with and without CSPMS. This was a comparative study which was carried out on 600 female students (300 free from CSPMS and 300 suffer from CSPMS) at Damanhur University, Elbehira governorate, Egypt. A modified version of Premenstrual Symptoms Screening Tool (PMSST) for clinicians was used to assess the severity of subject's PMS. Each subject was assigned to either CSPMS free group or CSPMS group based on the severity of their PMS symptoms. Then the HRQOL was assessed in the two groups, using a translated version of RAND36- item Health Survey Questionnaire. The study results indicated a statistically significant difference between the two groups in their total quality of life score. The quality of life among the free group was almost equally good or fair while poor quality of life was found among around one tenth (12\%) of CSPMS group compared to none among the free group. The largest proportion (86\%) among CSPMS group had fair quality of life. The most negatively affected domains were social functioning, role limitations due to physical health, role limitations due to emotional problems, energy/fatigue and emotional well-being respectively. The least affected domains were physical functioning and general health perception. On the other hand, bodily pain wasn't affected at all. The study findings revealed that girls with CSPMS suffer from poorer health-related quality of life than those without CSMPS. Appropriate PMS management strategies should be initiated in order to improve the health related quality of life among girls with CSPMS. The culture of silence surrounding PMS should be broken by focusing on researches that highlight its importance and negative impact on quality of life.
\end{abstract}

Keywords: Premenstrual Syndrome, Health Related Quality of Life, Girls

\section{Introduction}

Premenstrual syndrome [PMS] is one of the most common silent females' complains during their reproductive age. Until now, there's no exact clear definition for PMS but all its available definitions concluded that it is a cluster of distressing symptoms that co-appear 5-14 days before the menstrual shedding then co-evaporate one to two days after the time of shedding [1], [2]. Surveys indicate that PMS is among the most common health problems reported by reproductive age females where up to $90 \%$ of females had reported negative symptomatology during the luteal phase of their menstrual cycles. The Clinically Significant PMS (CSPMS) vary from $12.6 \%$ to $31 \%$ among females. [1], [3]

CSPMS refers to PMS symptoms that are severe enough to interfere with the normal daily life activities. The very severe form of PMS called premenstrual dystrophic disorder [PMDD] which is a psychiatric disorder that requires psychiatric intervention and hospitalization. [4] PMDD is excluded from 
the current study.

There are more than two hundred PMS reported symptoms which are classified as: physical, psychological and behavioral symptoms. Physical symptoms include: headache, back ache, gastrointestinal disturbances, breast tenderness, aches and bloating. Poor concentration, decreased interest, irritability, mood swings, anxiety/tension, and depression; are common PMS psychological symptoms. Finally, the common PMS behavioral symptoms are: social withdrawal, food craving, sleep disturbances and outburst of anger toward self and others. [1], [4]

The exact etiology of PMS is still vague but it seems to be complex and multifactorial. Yet, many theories had tried to explain its occurrence such as hormonal theory and psychosocial theory. Hormonal theory depends mainly on hormonal fluctuation during the luteal phase where progesterone is expected to be dominant. Consequently, PMS occurs when the estrogen dominate over progesterone during the luteal phase. [2] The psychosocial theory linked PMS to women's ambitions regarding their feminine identity. Therefore, many women are psychologically averse to their menstruation. They also may have negative or extreme thoughts that reinforce their aversion to premenstrual symptoms. In response, they develop inappropriate coping strategies such as mood swings or overeating which reduce their stress temporarily but also set them up to repeat the process month after month. [5]

The morbidity of PMS may be due the severity and chronicity of the symptoms.[2] In addition, the female reproductive age ranges between $15-45$ years. They have between 200 to 600 menstrual cycles over their reproductive years. Premenstrual symptoms peak during the luteal phase of menstrual cycle (5-11 days prior to menses). Accordingly, symptomatic females may spend from 3 to 18 years of their lives in a poor quality of life.

Quality of life (QOL) is a multidimensional construct that includes a person's subjective judgment of their overall life experience or congruence between desired and achieved life experiences. It is usually operationally defined by the tools used to measure it.[6] When the assessment of QOL is framed by a particular illness, it is termed health related quality of life (HR-QOL). The area of evaluating the impact of diseases on the light of quality of life depends mainly on the World Health Organization (WHO) definition of health as "A state of complete physical, mental, and social well-being and not merely the absence of disease or infirmity". [7] This depicts that the measurement of health and the effects of health care must include not only an indication of changes in the frequency and severity of diseases but also an estimation of well-being. This can be assessed by measuring the improvement in the quality of life related to health care. [8]

The health related quality of life dimensions varies from study to the other according to the tool used in its measurement. In the current study RAND36- item health survey will be used to assess quality of life. Thus, in the current study, health related quality of life contains eight dimensions namely: physical functioning, role limitation due to physical health, role limitation due to emotional problems, vitality/energy, emotional well-being, social functioning, bodily pain and general health. [9]

\subsection{Significance of the Study}

Based on many studies, premenstrual syndrome had a significant negative impact on the quality of life of the affected girls particularly school performance, social interactions, lifestyles, and emotional well-being. Difficulty in performing school functions and decrease in social interaction were the two most adversely affected parameters. [10], [11], [12] Identifying the exact relation between the severity of PMS symptoms and quality of life will help to highlight the significance of PMS. Hence, this may help in breaking the culture of silence and negligence surrounding PMS. It also may contribute to enriching the nursing data base about the quality of life dimensions that needs much attention and care with PMS.

\subsection{Aim of the Study}

Compare the Quality of life among girls with or without CSPMS.

\subsection{Research Hypothesis}

Hypothesis: girls without CSPMS have better quality of life than CSPMS suffers

\section{Subjects and Methods}

\subsection{Operational Definition}

Clinically significant premenstrual syndrome (CSPMS): those who have moderate or severe premenstrual symptoms according to the premenstrual symptoms screening tool for clinical (PMSST). [13]

\subsection{Research Design}

Comparative descriptive research design was utilized to carry out this study

\subsection{Setting}

This study was conducted in five colleges out of ten /Damanhur University, Elbehira governorate affiliated to ministry of higher education. The colleges were randomly selected from previously prepared list [College of Science, Art, Nursing, Education and Social Work college]

\subsection{Subjects}

The subjects of the present study included 600 female university students (300 CSPMS suffers and 300 CSPMS free) based on PMSST. [13] Using the multistage sampling technique, the following steps were conducted to select the students:-

- Five colleges out of the ten colleges at Damanhur University, El-Beheira Governorate were randomly 
selected from the previously prepared sampling frame.

- From each college, a sampling frame including all the female students in each academic year was prepared with the help of the student affairs. Then, 120 female students were chosen from each college using equal allocation.

- In each college, 30 female students from each academic year (15 CSPMS suffers and 15 CSPMS free based on PMSST) [13] were selected using stratified sampling technique from each academic year using equal allocation. The female students was chosen based on the following inclusion criteria:

i Had regular menstruation [22-35 days] during the last 12 months.

ii Free from any medical diseases as well as any pelvic disorders.

iii Willing to participate in the study.

iv Unmarried

- From the selected students CSPMS [moderate and severe] suffers were assigned to CSPMS group and the free girls and girls with mild PMS were assigned to the other group. Sample was calculated according to the following equation: $n=\frac{N}{1+N[e]^{2}}$

Where (n) is the sample size, $(\mathrm{N})$ is the population size and (e) is the level of precision $=0.05$.

\subsection{Tools of Data Collection}

Three tools were used for data collection:

\subsubsection{First Tool}

Demographic data and menstrual history structured interview schedule: It was developed by the researchers to collect data related to socio-demographic characteristics such as: age, and residence. It also included the menstrual history such as: age at menarche, menstrual interval, duration, amount of blood flow and date of the last menstrual period.

\subsubsection{Second Tool}

A modified version of premenstrual symptoms screening tool for clinicians (PMSST).[1] PMSST is a questionnaire used for the diagnosis of PMS and was first introduced by Steinner et al. in 2003. It was used to assess PMS physical (14 items), psychological (12 items) and behavioral (6 items) symptoms. The total is 32 likert-scaled items rated on four alternatives: (0) absent, (1) mild, (2) moderate, and (3) severe.
This tool was translated into Arabic by the researchers.

Scoring system:

The total symptoms score ranged from 0 to 96 . The subject was considered to have:

- No PMS if her total score $\leq 24$

- Mild PMS if her total score 25-48

- Moderate PMS if her total score 49-72

- Severe PMS if her total score $\geq 73$

\subsubsection{Third Tool}

A translated version of RAND-36 item health Survey. [14]

This tool named RAND in affiliation to RAND Corporation (Research and Development). This tool was originally developed by Ware JE, Sherbourne CD at 1992 as a part of medical outcomes project then modified by Hays R at 1993 to RAND 36-item [9]. Later on, it was translated into several languages. The Arabic format was taken from Abdulaziz S et als [14] then modified by the researcher. It composed of two parts:

Part 1: This tool assess the health related quality of life through eight domains: physical functioning(10 items), role limitation due to physical health (4items), role limitation due to emotional problems (3items), vitality/energy (4items), emotional well-being (5 items), social functioning (2 items), bodily pain (2items) and general health (5items). Furthermore, one question is concerned with assessment of the health change after the health problem.

According to RAND Corporation "Scoring the RAND 36-Item Health Survey is a two-step process". In step1, the pre-coded numeric values were recorded according to the scoring key given in Table 1. All the items were scored so that a high score defined a more favorable health state. In addition, each item was scored on a 0 to 100 range so that the lowest and highest possible scores were 0 and 100 , respectively. In step 2, items in the same scale were averaged together to create the 8 scale scores. Table 1 lists the items averaged together to create each scale score. Items that were left blank [missing data] were not taken into account when calculating the scale scores. Hence, scale scores represent the average for all items in the scale that the respondent answered. The scale composed of 36 likert-scaled items with five alternatives from the most positive to the most negative as follows: (100) always, (75) most of the times, (50) sometimes, (25) rarely or (0) never. For the negative items the scoring were reversed [15].

Table 1. Scoring system.

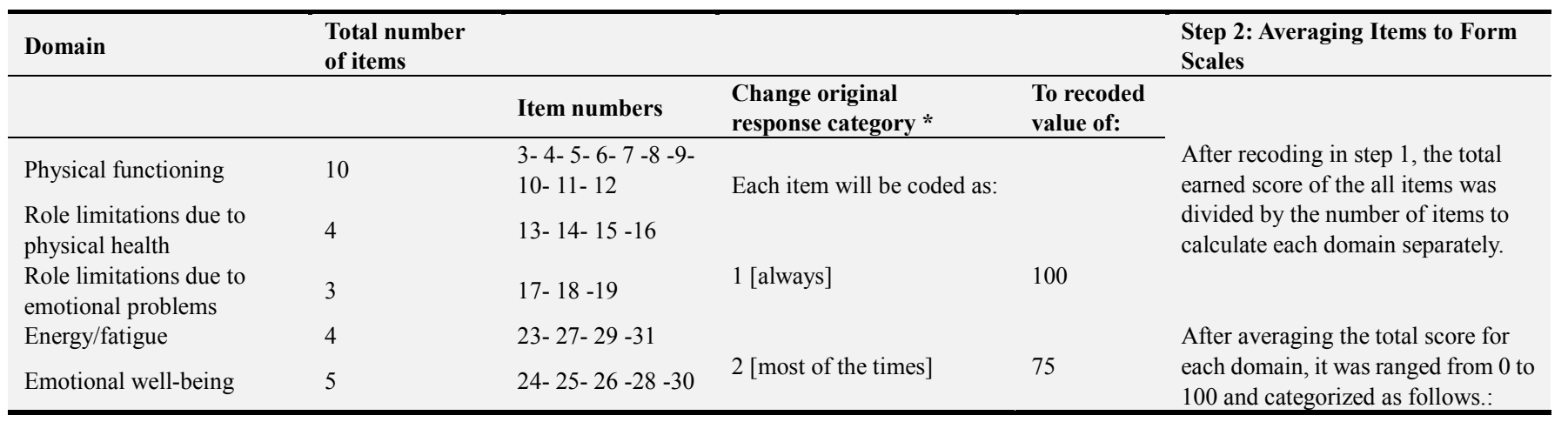




\begin{tabular}{|c|c|c|c|c|c|}
\hline Domain & $\begin{array}{l}\text { Total number } \\
\text { of items }\end{array}$ & & & & $\begin{array}{l}\text { Step 2: Averaging Items to Form } \\
\text { Scales }\end{array}$ \\
\hline Social functioning & 2 & $20-32$ & \multirow{2}{*}{3 [sometimes] } & & \multirow{4}{*}{$\begin{array}{l}\text { Poor }>60 \\
\text { Fair } 60<75 \\
\text { Good } \geq 75\end{array}$} \\
\hline Bodily Pain & 2 & $21-22$ & & 50 & \\
\hline General health & 5 & $1-33-34-35-36$ & 4 rarely or & 25 & \\
\hline Health changes & 1 & 2 & 5 [never] & 0 & \\
\hline Total RAND & 36 & \multicolumn{4}{|c|}{$\begin{array}{l}\text { After calculation of the eight RAND domains the total score was calculated through summing the eight } \\
\text { domains score then divided by eight. The total HRQOL score ranged from } 0-100 \text { and categorized as } \\
\text { follows:- Poor }<60 \text { Fair } 60<75 \text { Good } \geq 75\end{array}$} \\
\hline
\end{tabular}

* Pre-coded response choices as printed in the questionnaire.

Source: http://www.rand.org/health/surveys_tools/mos/36-item-short-form/scoring.html

Part 2: three open ended questions to specify the most important life goals and to what extent it has been impaired due to the studied health problems.

\subsection{Tools Validity and Reliability}

All tools were tested for reliability by test-retest and for content validity by a jury of 5 experts in the field and one expert from the biostatistics. The internal consistency of the tools was done using Cronbach Alpha Coefficient. The results were statistically acceptable $(0.69,0.72,0.70)$ for tool I,II, and III, respectively.

\subsection{Ethical Considerations}

An official agreement to conduct the study had been obtained from Damanhur University then from the dean of each college included in the study after explaining its purpose. The purpose of the study was explained to each student and an oral consent for participation in the study was obtained from each one of them. The confidentiality of students' information to be used only for research purpose was assured. Furthermore, their freedom for participation in the study and withdrawal at any time was assured.

\subsection{Field Work}

- Pilot study was carried out on randomly selected 30 female university students from one college not included in the actual study (Pharmacy College). The necessary modifications were done accordingly.
- Data collection: The students were interviewed in groups either in the lecture room; laboratory or library. During the interview, the researcher had read each item/ question on the data collection sheet and explained its meaning to the student. The student was asked to write down her answer immediately following asking each item/ question. The interview time ranged from $20-25$ minutes. Student was allowed to ask for any elaboration or explanation. After the interview the researcher gave each group of the study subjects a brief talk about PMS, it's possible relation to their quality of life and its possible management. This was done in the lecture rooms with the assistance of some staff members in each college. The time for data collection was from 9 am to 2 pm. Data was collected 2 days per week, 20-30 girls were interviewed per day for a period of 3 months, started on March to the end of May 2016.

\subsection{Statistical Analysis}

Data was fed, coded, edited and analyzed using PC with Statistical Package for Social Science [SPSS] version 20 for windows. The following statistical measures were used: Frequency\& percentage used for describing and summarizing categorical data. Cross tabulation was used with percentage to explore relationships between variables. Pearson Chi square $\left(\mathrm{X}^{2}\right)$, Fisher's Exact Test $(\mathrm{F})$ and Monte Carlo $\left({ }^{\mathrm{MC}} \mathrm{P}\right)$ testes were used to test the significance between the two groups. The 0.05 level was used as the cut off value (P value) for statistical significance.

\section{Results}

Table 2. Number and percent distribution of the study subjects according to their age, residence and age at menarche.

\begin{tabular}{|c|c|c|c|c|c|}
\hline \multirow{2}{*}{ Socio-demographic characteristics } & \multicolumn{2}{|c|}{ CSPMS free group } & \multicolumn{2}{|c|}{ CSPMS group } & \multirow{2}{*}{$P$ value } \\
\hline & No [300] & $\%$ & No [300] & $\%$ & \\
\hline \multicolumn{6}{|l|}{ Age [years] } \\
\hline $19<21$ & 150 & 50.0 & 144 & 48.0 & $\mathrm{P}=0.087$ \\
\hline $21-24$ & 150 & 50.0 & 156 & 52.0 & \\
\hline \multicolumn{6}{|l|}{ Residence } \\
\hline Rural & 226 & 75.3 & 216 & 72.0 & $\mathrm{P}=0.084$ \\
\hline Urban & 74 & 24.7 & 84 & 28.0 & \\
\hline \multicolumn{6}{|l|}{ Age at menarche [years] } \\
\hline $9<12$ & 52 & 17.3 & 166 & 55.3 & \\
\hline $12<15$ & 204 & 68.0 & 98 & 32.7 & $\mathrm{P}=0.0001^{*}$ \\
\hline$\geq 15$ & 44 & 14.7 & 36 & 12.0 & \\
\hline
\end{tabular}

P: Pearson Chi-Square *Significant at 0.05 
Table [2] indicates absence of any significant differences between the two groups in relation to their age and residence. Around one-half $(50.0 \%, 48.0 \%)$ of free group and CSPMS group aged $19<21$ years, respectively. Around three-quarters among both free group (75.3\%) and CSPMS group $(72.0 \%)$ were rural residents with no statistically significant difference between the two groups. A statistically significant difference was observed between the two groups in relation to age at menarche. Around two-thirds $(68.0 \%)$ of the free group had their menarche at age of $12<15$ years compared to only $32.7 \%$ of the CSPMS group.

Table 3. Number and percent distribution of the study subjects according to the severity of their PMS symptoms.

\begin{tabular}{|c|c|c|c|c|c|c|}
\hline & \multirow{2}{*}{ Severity of PMS symptoms } & \multicolumn{2}{|c|}{ CSPMS free group } & \multicolumn{2}{|c|}{ CSPMS group } & \multirow{2}{*}{ P value } \\
\hline & & No [300] & $\%$ & No [300] & $\%$ & \\
\hline \multirow{4}{*}{ Physical symptoms } & Absent & 142 & 47.3 & 0 & 0.0 & \multirow{4}{*}{${ }^{\mathrm{MC}} \mathrm{P}=0.0001 *$} \\
\hline & Mild & 138 & 46 & 70 & 23.3 & \\
\hline & Moderate & 20 & 6.7 & 144 & 48.0 & \\
\hline & Severe & 0 & 0.0 & 86 & 28.7 & \\
\hline \multirow{3}{*}{ Psychological symptoms } & Absent & 144 & 48.0 & 0 & 0.0 & \multirow{3}{*}{${ }^{\mathrm{MC}} \mathrm{P}=0.0001^{*}$} \\
\hline & Moderate & 20 & 6.7 & 94 & 31.3 & \\
\hline & Severe & 4 & 1.3 & 182 & 60.7 & \\
\hline \multirow{4}{*}{ Behavioural symptoms } & Absent & 204 & 68.0 & 0 & 0.0 & \multirow{4}{*}{${ }^{\mathrm{MC}} \mathrm{P}=0.0001 *$} \\
\hline & Mild & 86 & 28.7 & 44 & 14.7 & \\
\hline & Moderate & 10 & 3.3 & 230 & 76.7 & \\
\hline & Severe & 0 & 0.0 & 26 & 8.6 & \\
\hline \multirow{3}{*}{ Total score of PMS } & Mild & 156 & 52.0 & 0.0 & 0.0 & \multirow{3}{*}{${ }^{\mathrm{MC}} \mathrm{P}=0.0001 *$} \\
\hline & Moderate & 0 & 0.0 & 140 & 46.7 & \\
\hline & Severe & 0 & 0.0 & 160 & 53.3 & \\
\hline
\end{tabular}

${ }^{\mathrm{MC}} \mathrm{P}$ : Monte Carlo *Significant at 0.05

According to Table [3], there was a statistically significant difference $\left({ }^{\mathrm{MC}} \mathrm{P}<0.0001\right)$ between the two groups in all types of PMS symptoms. More than one-quarter (28.7\%) of CSPMS group had severe PMS physical symptoms compared to non among the free group. Less than two-thirds $(60.7 \%)$ of CSPMS group had complained from severe PMS psychological symptoms compared to only $1.3 \%$ among the free group. More than three-quarters (76.7\%) of CSPMS group had moderate PMS behavioral symptoms compared to only $3.3 \%$ among the free group. Thus, the pattern appeared was that the free group was almost equally divided between having either absence or mild PMS where the CSPMS group that was nearly divided between having moderate and severe PMS.

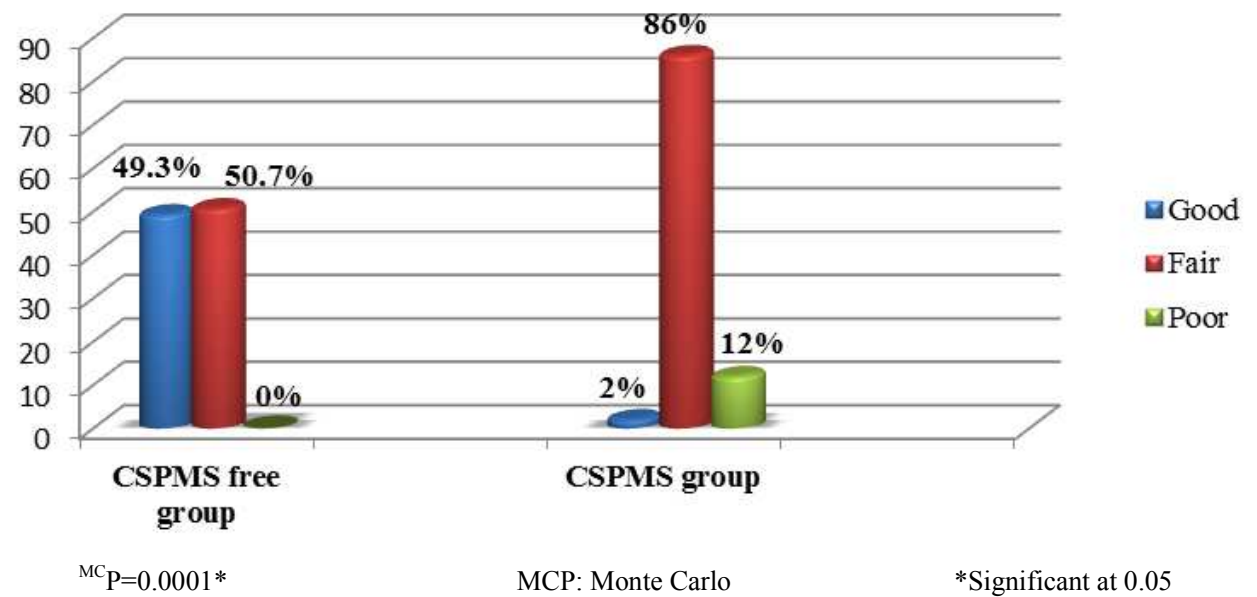

Figure 1. Percent distribution of the study subjects according to the relation between the severity of their PMS symptoms and their total HRQOL score.

Figure 1 illustrates the presence of a statistically significant difference between the two groups in their total quality of life score $(\mathrm{P}=0.001 *)$. The free group has almost equally good or fair quality of life $(49.3 \%, 50.7 \%)$ respectively. Conversely, the largest proportion (86.0\%) among CSPMS had fair quality of life and $12.0 \%$ of them had poor quality of life compared to none among the free group. 
Table 4. Number and percent distribution of the study subjects according to relation between the severity of their PMS symptoms and each domain of their HRQOL.

\begin{tabular}{|c|c|c|c|c|c|}
\hline \multirow{2}{*}{ Quality of life score } & \multicolumn{2}{|c|}{ CSPMS free group } & \multicolumn{2}{|c|}{ CSPMS group } & \multirow{2}{*}{$P$ value } \\
\hline & No [300] & $\%$ & No [300] & $\%$ & \\
\hline \multicolumn{6}{|l|}{ Physical functioning } \\
\hline Good & 90 & 30.0 & 18 & 6.0 & \multirow{3}{*}{$\mathrm{MCP}=0.0001 *$} \\
\hline Fair & 188 & 62.7 & 268 & 89.3 & \\
\hline Poor & 22 & 7.3 & 14 & 4.7 & \\
\hline \multicolumn{6}{|l|}{ Emotional well-being } \\
\hline Good & 160 & 53.3 & 12 & 4.0 & \multirow{3}{*}{$\mathrm{MCP}=0.0001 *$} \\
\hline Fair & 118 & 39.3 & 222 & 74.0 & \\
\hline Poor & 22 & 7.4 & 66 & 22.0 & \\
\hline \multicolumn{6}{|c|}{ Role limitations due to physical health } \\
\hline Good & 206 & 68.7 & 6 & 2.0 & \multirow{3}{*}{$\mathrm{MCP}=0.0001^{*}$} \\
\hline Fair & 76 & 25.3 & 42 & 14.0 & \\
\hline Poor & 18 & 6.0 & 252 & 84.0 & \\
\hline \multicolumn{6}{|c|}{ Role limitations due to emotional problems } \\
\hline Good & 90 & 30.0 & 90 & 30.0 & \multirow{3}{*}{$\mathrm{MCP}=0.021 *$} \\
\hline Fair & 106 & 35.3 & 44 & 14.7 & \\
\hline Poor & 104 & 34.7 & 166 & 55.3 & \\
\hline \multicolumn{6}{|l|}{ Energy/fatigue } \\
\hline Good & 84 & 28.0 & 52 & 17.3 & \multirow{3}{*}{$\mathrm{P}=0.0001 *$} \\
\hline Fair & 192 & 64.0 & 158 & 52.7 & \\
\hline Poor & 24 & 8.0 & 90 & 30.0 & \\
\hline \multicolumn{6}{|l|}{ Social functioning } \\
\hline Good & 232 & 77.3 & 10 & 3.4 & \multirow{3}{*}{$\mathrm{P}=0.0001 *$} \\
\hline Fair & 54 & 18.0 & 22 & 7.3 & \\
\hline Poor & 14 & 4.7 & 268 & 89.3 & \\
\hline \multicolumn{6}{|l|}{ Bodily pain } \\
\hline Good & 200 & 66.7 & 190 & 63.3 & \multirow{3}{*}{$\mathrm{F}=0.080$} \\
\hline Fair & 100 & 33.3 & 110 & 36.7 & \\
\hline Poor & 0 & 0.0 & 0 & 0.0 & \\
\hline \multicolumn{6}{|l|}{ General health } \\
\hline Good & 90 & 30.0 & 18 & 6.0 & \multirow{3}{*}{${ }^{\mathrm{MC}} \mathrm{P}=0.0001 *$} \\
\hline Fair & 188 & 62.7 & 268 & 89.3 & \\
\hline Poor & 22 & 7.3 & 14 & 4.7 & \\
\hline
\end{tabular}

Table 4 summarizes the relation between the severity of PMS symptoms and each domain in the HRQOL. It is observed that there is a statistically significant relation between the severity of PMS symptoms and all HRQOL domains except for bodily pain. It is clear that $30.0 \%$ of the CSPMS free group has good physical functioning during the premenstrual period compared to only $6.0 \%$ of the CSPMS group. Furthermore, more than one-half [53.3\%] of the CSPMS free group has good emotional wellbeing during their premenstrual period compared to only $4.0 \%$ among CSPMS group. Again, $68.7 \%$ of the CSPMS free group has no role limitations due to physical health compared to $2.0 \%$ of the CSPMS group. On the other hand, only $34.7 \%$ of the CSPMS free group has role limitation due to emotional problems compared to $55.3 \%$ of the other group. As regard, energy and vitality only $8.0 \%$ of CSPMS free group has a sense of poor energy compared to $30 \%$ of the CSPMS group. In addition, less than one third [30\%] of the free group has good perception of their health status compared to only $6.0 \%$ of the CSPMS group. The majority [89.3\%] of CSPMS group had poor social functioning compared to only $4.3 \%$ of CSPMS free group. Moreover, around two thirds of the both groups did not complain from bodily pain $[63.3 \%, 66.7 \%$ respectively] 


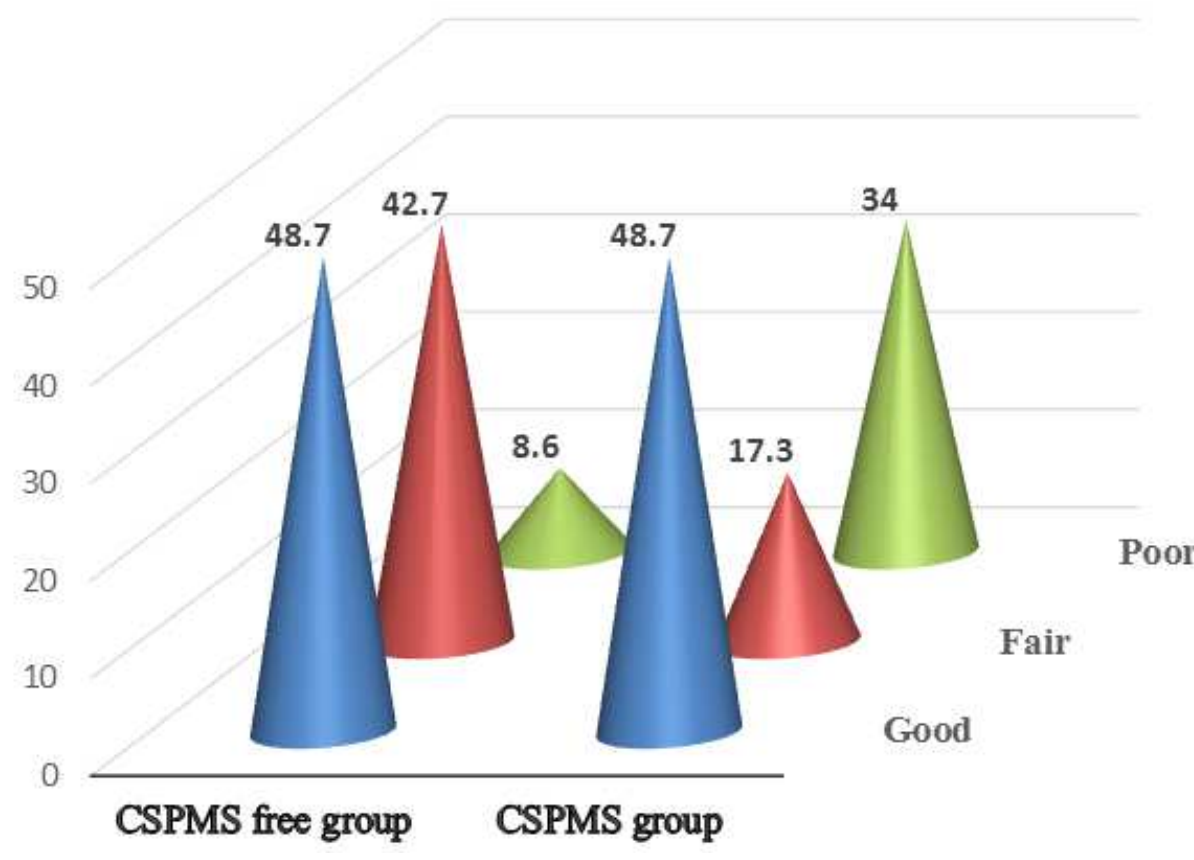

Good

- Fair

Eoor

$\mathrm{MCP}=0.004 * \mathrm{MCP}:$ Monte Carlo *Significant at 0.05

Figure 2. Percent distribution of the study subjects according to the relation between the severity of their PMS symptoms and their health perception after menarche.

According to figure 2 only $8.6 \%$ of the CSPMS free group compared to $34.0 \%$ of CSPMS group had reported that their health status became poorer after menarche than before it.

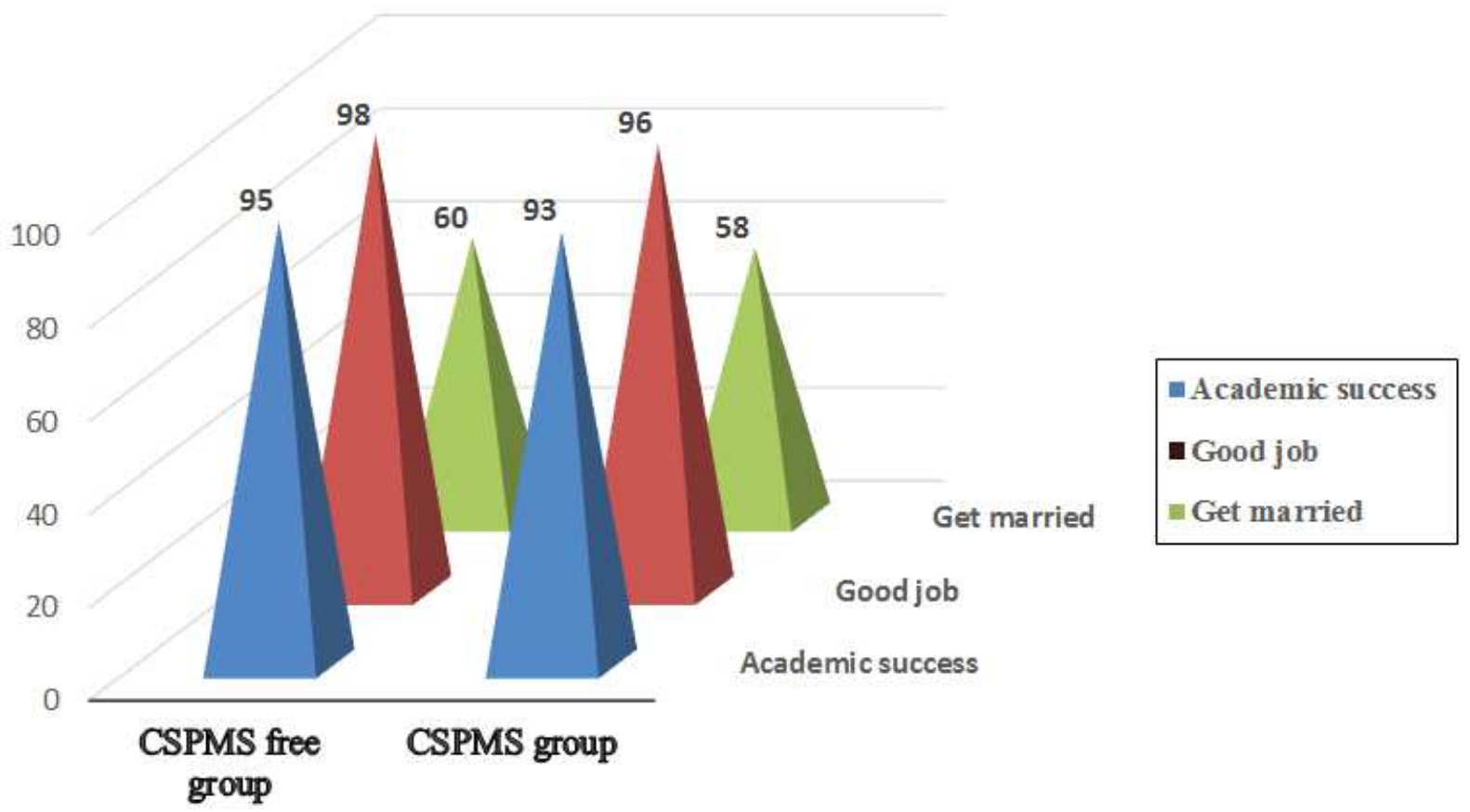

Total is not exclusive P: Pearson Chi-Square $=0.093$

Figure 3. Percent distribution of the study subjects according to their most important life goals.

Figure 3 shows that there is no statistical significant difference between the two groups in relation to their life goals. The most common reported goal was good job [98.0\% and 96.0\%] for CSPMS free group and CSPMS group respectively. The second reported life goal was academic success which represents $95.0 \%$ among CSPMS free group and 93.0\% among CSPMS group. Finally, getting married represent the least represented life goals as it was mentioned by only $58.0 \%$ of the CSPMS group compared to $60.0 \%$ among the other group. 
Table 5. Number and percent distribution of the study subjects according to the relation between the severity of their PMS symptoms and their perceived academic achievement.

\begin{tabular}{|c|c|c|c|c|c|c|}
\hline \multirow{2}{*}{\multicolumn{2}{|c|}{ Perceived Academic Achievement }} & \multicolumn{2}{|c|}{ CSPMS free group } & \multicolumn{2}{|c|}{ CSPMS group } & \multirow{2}{*}{ Significance test $[\mathrm{P}$ value $]$} \\
\hline & & No [300] & $\%$ & No[300] & $\%$ & \\
\hline \multirow{3}{*}{$\begin{array}{l}\text { Attention during study either at class or } \\
\text { at home. }\end{array}$} & Good & 208 & 69.3 & 20 & 6.7 & \multirow{3}{*}{$\mathrm{P}=0.0001^{*}$} \\
\hline & Fair & 80 & 26.7 & 36 & 12.0 & \\
\hline & Poor & 12 & 4.0 & 244 & 81.3 & \\
\hline \multirow{3}{*}{ Absenteeism days } & Not affected & 132 & 44.0 & 40 & 13.3 & \multirow{3}{*}{$\mathrm{P}=0.0001^{*}$} \\
\hline & Modestly affected & 136 & 45.3 & 162 & 54.0 & \\
\hline & Severely affected & 32 & 10.7 & 98 & 32.7 & \\
\hline \multirow{3}{*}{ Ability to work during practical training } & Good & 228 & 76.0 & 96 & 32.0 & \multirow{3}{*}{${ }^{\mathrm{MC}} \mathrm{P}=0.0001 *$} \\
\hline & Fair & 68 & 22.7 & 58 & 19.3 & \\
\hline & Poor & 4 & 1.3 & 146 & 48.7 & \\
\hline \multirow{3}{*}{ Total perceived academic achievement } & Good & 235 & 78.3 & 100 & 33.3 & \multirow{3}{*}{${ }^{\mathrm{MC}} \mathrm{P}=0.0001 *$} \\
\hline & Fair & 60 & 20.0 & 60 & 20.0 & \\
\hline & Poor & 5 & 1.7 & 140 & 46.7 & \\
\hline
\end{tabular}

${ }^{\mathrm{MC}} \mathrm{P}$ : Monte Carlo P: Pearson Chi-Square *Significant at 0.05

According to Table 5, there is a statistically significant difference between the two groups in all aspect of their perceived academic achievement. More than two-thirds [69.3\%] of the CSPMS free group had reported good attention during study either at home or at class. However, the largest proportion [81.3\%] of CSPMS group reported poor attention. Forty-four percent of CSPMS free group had reported no effect of PMS symptoms on their absenteeism compared to only $13.3 \%$ among CSPMS group. Only $1.3 \%$ of the CSMPS free group had reported that PMS symptoms poorly affect their ability to work during practical training compared to nearly half [48.7\%] of the CSPMS group. Consequently, only $1.7 \%$ of the CSPMS free group judged their perceived academic performance as poor compared to $46.7 \%$ of the CSPMS group.

\section{Discussion}

The CSPMS is assumed to significantly impair the girl's health related quality of life. Yet, it is one of the most neglected women health problems in the developing countries in general and in Egypt in specific. The results of the present study indicated a statistically significant difference between CSPMS group and CSPMS free group in their total quality of life scorewhere CSPMS group had lower quality of life score compared to the free group. The most affected domains were social functioning, role limitations due to physical health, role limitations due to emotional problems, energy/fatigue and emotional well-being, respectively. Otherwise, the least affected domains were physical functioning and general health perception. On the other hand, bodily pain wasn't affected at all.

This result is in accordance with numerous studies. First,Farrokh-Eslamlou $\mathrm{H}$ et al (2015) [12]studied premenstrual syndrome and quality of life among Iranian medical students. They found that moderate and severe PMS adversely affects the social relationship, mental and environmental aspects of quality of life while having little effect on physical wellbeing.
Second, Ahmad M and Fahad S (2014)[3] had studied the prevalence of premenstrual syndrome and its impact on quality of life among university medical students, El-Qassim University, KSA. This study showed that students with moderate to severe PMS reported poorer health-related quality of life than PMS free group. The burden of PMS on health-related quality of life was on mental and emotional domains. Although they further stressed that the domain of physical wellbeing and vitality are not affected by the severity of PMS, they explained that the observed role limitation among their study subjects was due to the PMS physical symptoms.

Third,Delara M et al (2012)[16] had conducted a study about health related quality of life among adolescents with premenstrual disorders in Sabzevar city /Iran. They reported that PMS severely affect health related quality of life score where more than one-half among their participants had poor quality of life. Students with moderate to severe PMS scored significantly lower in all quality of life aspects except for physical functioning. The differences were more evident in both emotional aspect and social functioning.

Delara $\mathrm{M}$ et al [16] had reported too much lower quality of life score among their subjects who suffered from moderate to severe PMS than the current study. Otherwise, in the current study more than one tenth $(12.0 \%)$ of CSPMS group had poor quality of life compared to more than half $(52.0 \%)$ in Delara et al's study. This difference might be attributed to the age difference between the two samples wherein the former it was early adolescent (14-19 years) while in the later they were in late adolescence to early adult (19-24 years). This can be explained by the fact that early adolescence is characterized by emotional liability and increased tendency to complain more than late adolescence and early adulthood. In addition to, the new experience of menstruation which exaggerates more anxiety and fear especially if it is burdened by PMS which in turn may negatively affect the health related quality of life.[17]

Fourth, Schiola A et al (2011)[4] had assessed the burden of moderate/severe premenstrual syndrome and premenstrual 
dysphoric disorder in a cohort of Latin American women. They reported significant burden of moderate and severe PMS on quality of life. The most affected aspects among their subjects were productivity at work, independence and financial burden. They correlated loss of productivity to the bad psychological wellbeing. Fifth, Baba Aissa et al (2010)[18] had studied premenstrual dysphoric disorder among medical students at a Nigerian university. They found that PMS of moderate/severe intensity was significantly correlated with poor psychological wellbeing. It also had devastating effect on the student's social interaction and independence and had mild effect on their physical health.

The findings of the present study are also in line with some relevant literatures. Some experts had reported that although PMS physical symptoms are devastating and obvious, the psychological and social symptoms are perceived to be more severe and have negative impact on health related quality of life. They further added that in many cases the psychological burden is the underlying cause of the PMS physical symptoms due to the process of somatization. [19], [20]

On the contrary, other studies although reported negative PMS impact on the health related quality of life as a whole but the most affected domains were different from the current study. They declared that the most affected domains were physical wellbeing and independence and the least affected domain was psychological wellbeing. This result is mentioned by at least six studies. First, Mustafa R et al (2013)[10] had investigated the relation between PMS and quality of life at University Hospital of Sindh/ Iran. They reported that CSPMS had a significant negative impact on quality of life. The main affected domain among their participants was physical wellbeing. They further added that higher absenteeism days from work and less productivity were more prevalent among their participants. They correlated such work impairment to the bad physical health during the premenstrual period.

Second and third, Brohi ZP et al (2011) [21] and Pinar G et al (2011) [22] indicated a significant impact of CSPMS on physical aspect of quality of life where its impact on psychological wellbeing, social relationship and environmental area was mild. The former conducted a Jordan study about the frequency and impact of premenstrual syndrome on quality of life among Isra University student. The later studied premenstrual syndrome in Turkish college students and its effects on quality of life.

Fourth and fifth, Lothar A et al (2010)[11] and Dennerstein L et al (2010) [23] had studied the impact of premenstrual disorders on the daily functioning and quality of life among women. The former conducted his study in Berlin while the later conducted it in Asia. Both of them concluded that moderate and severe PMS has significant burden on health related quality of life. A significant impact on activities of women's daily life was reported with the type of activity differing by how women predominantly spend their time. Both of them related such impairment in the daily life activities to the poor physical health caused by CSPMS.

Sixth, Yang M, et al (2008)[24] conducted a study about burden of premenstrual dysphoric disorder on health-related quality of life among USA women via internet survey. They concluded that CSPMS had significant impact on the physical wellbeing among their participants especially those who had chronic diseases. They further added that the burden of PMS is largely placed on women between 18 and 45 years who have great responsibilities in school, family, and work. The difference between the current study and Yang $M$ etal's one might be attributed to the added physical burden of chronic diseases in Yang $M$ et al study. Conversely, the current study sample was disease free so their physical burden is expected to be lower.

In the current study, only small proportion $(8.6 \%)$ of the CSPMS free group reported that their health has become poorer after menarche than before it compared to $34.0 \%$ among CSPMS group. Their justification was related to both psychological and physical symptoms of PMS. In fact, there are no available evidences comparing the girls' health perception before and after menarche with different degrees of PMS. The available references described only the health perception at time of menarche. The current study support the hypothesis that the more the girl is in stress (moderate and severe PMS), the more she perceives menarche as a disease that hinder her health. This assumption is supported by many studies.

A recent Mexican study conducted by Luisa M and Herrera $\mathrm{V}$ (2014)[25] about age at menarche, reactions to menarche and attitudes towards menstruation among adolescent girls, reported that after menarche the most frequent reactions were worry and feeling odd. The negative attitude was associated with less preparation and high level of stress.

An earlier study conducted by Sadiq M and Salih A (2013)[26] studied the knowledge and practice of adolescent females about menstruation in Baghdad. They reported that $66.0 \%$ among their study participants had perceived their menses as kind of illness or evil which is reflected on their self-evaluation of their health after menarche. This study reported too much higher percentage of girls who perceived their health as poor after menarche than the present study. This difference may be justified by the age differences between the two studies samples. The present study sample aged 19 to 24 years where the later study sample was $14-19$ years. It is clear from many evidences that early adolescents pay too much attention to the changes occurred in their bodies. Consequently, they may interpret some discomforts that take place with menarche as poor health. Another determinant contributing to poor health perception after menarche is the fact that adolescence is normally a time of remarkable change in which many different aspects of life such as physical, emotional, intellectual, academic, social and spiritual aspects are disrupted. The problem is further complicated by the fact that these changes join simultaneously and not constantly in harmony. For girls, the misunderstanding accompanying various bodily and hormonal changes is complicated by the conflicting social massages that girls receiving continuously from others.[27]

Additionally, Dube SH and Sharma K (2012)[28] had conducted Indian study about knowledge, attitude and practice 
regarding reproductive health among urban and rural girls. They reported that at least one third among both urban and rural girls think that menstruation is some kind of disease or a physical problem such as internal bleeding. Consequently, their health is expected to be poorer after menarche than before it.

Janet Lee(2008)[29] studied the relation between mothers and daughters at menarche time. She finds that young mothers are more supportive and emotionally engaged with their daughters so they can decrease stress associated with menarche. Nonetheless, this study still suggests that emotionally connected mothers are able to mitigate feelings of shame, humiliation and illness associated with the discourses of menstruation in contemporary cultures. Therefore, even in the presence of maternal support menarche is still perceived as a health problem which indicates poor health perception after menarche.

An earlier study conducted by Anne M (2004)[30] discussed the adolescent girls' perception of their families interaction related to menarche. The author concluded that girls from different nationalities [14-18 years of age]from both high and low income families were more liable to connect fear, shame, dysfunction, and victimization with their bodies following menarche when sex and reproduction were abandoned.

A contradictory result had been reported in the open societies where discussion about menstruation is open. For example, Gun I et al (2006) [31] had conducted a Sweden study about girls' attitudes and feelings towards menstruation and womanhood at menarche. He indicated that the largest proportion among their participants enjoying their transition from childhood to womanhood and so they like their body growing. Consequently, they have more optimistic feeling towards menstruation. Furthermore, mothers' timing and capability to convey positive attitudes towards menstruation and the body is important. Peoples surrounding the girls also play vital role in her smooth transition to womanhood. The end result will be positive health perception after menarche than before it.

In the present study, the most common reported life goal was good job for both groups. Academic success came in the second priority and getting married represent the last life goal for both groups. All of them agreed that academic achievement is the first step in achieving their life goals. Consequently, further assessment for the relation between the severity of PMS and academic success was done. The results showed a statistically significant difference between the two groups in all aspect of their perceived academic achievement. PMS was reported to have negative impact on attention during study at home or at class, absenteeism, work during practical training and perceived academic performance as a whole.

Such poor academic achievement for CSPMS suffers was reported in numerous studies. First,Kavita $\mathrm{S}$ and Nagaraj $\mathrm{CH}(2014)$ [32] studied the frequency and effect of dysmenorrhea and premenstrual syndrome on daily life activities of adolescent girls in rural areas of Bangalore. They reported that CSPMS had negative effect on both school attendance and concentration during class room time.

Second, Florence E et al (2011)[33] assessed the prevalence and effect of premenstrual dystrophic disorder on nursing students' academic performance and clinical training in Kuwait. They reported that there is a statistically significant correlation between the severity of PMS and frequent absenteeism and penalties. As regard to the academic performance, they further added that although all students believe that PMS severely affect their academic performance, their GPA doesn't support this believe. Third, Diaa E et al (2006)[34] studied the prevalence and impact of premenstrual syndrome in adolescent girls schooling in United Arab Emirates. They concluded that CSPMS had caused significant deterioration in the girl's school performance. They further elaborated that severe PMS is associated with more absenteeism and less participation in school activities.

Fourth, Nisar N et a (2008) [35] who studied the frequency, intensity and impact of premenstrual syndrome in medical students in Isra University hospital/ Sindh /Pakistan. They reported that CSPMS adversely affects the student's academic achievement among medical students. The most obvious effect was frequent absenteeism and low grading at PMS time. Fifth, Tenkir A et al (2002)[36] conducted a study about the prevalence and effect of PMS on academic and social performance in students in Jimma University, Ethiopia. They revealed that around $16.0 \%$ of their study participants frequently missed classes and $15.0 \%$ missed examination or scored lower grads at least once because of PMS symptoms. No available contradictory studies were found.

\section{Conclusion}

The results of the present study indicated that CSPMS group had lower quality of life score compared to the free group. Specifically, the most affected domains were social functioning, role limitations due to physical health, role limitations due to emotional problems, energy/fatigue and emotional well-being respectively. However, the least affected domains were physical functioning and general health perception. On the other hand, bodily pain wasn't affected at all. Moreover, a negative impact on academic achievement is also reported inform of poor attention, frequent absenteeism and poor performance during clinical training.

\section{Recommendations}

- Educational program should be introduced to the educational organizations [schools and universities] about PMS and its suitable interventions.

- Mass media campaigns to increase the community awareness about PMS and fight the culture of silence surrounding it.

- Establish community based support groups for moderate/severe PMS sufferers and PMS hotlines to expand the supportive network for girls.

- Researches should be directed to find effective 
interventions for PMS in order to decrease its burden on the girls' quality of life.

- Further researches should also be done to compare quality of life during both follicular and luteal phase of the menstrual cycle.

\section{Acknowledgements}

The researchers would like to express their greatest thanks and appreciation to the students who participated in this research for their cooperation.

\section{References}

[1] Naeimi N. The Prevalence and Symptoms of Premenstrual Syndrome under Examination. Journal of Biosciences and Medicines 2015; 3 [8]: 1-8.

[2] Khajehei M [2015]Etiology, Diagnosis and Management of Premenstrual Syndrome. J Pain Relief 2015; 4 [2]: 185-193. doi: $10.4172 / 21670846.1000193$.

[3] Ahmad M,Fahad S. Prevalence of Premenstrual Syndrome and its Impact on Quality of Life among University Medical Students, Al Qassim University, KSA. The journal of Public Health Research 2014; 4 [1]: 1-6. DOI: 10.5923/j.phr.20140401.01.

[4] Schiola A,Lowin J, Lindemann M, Patel R, Endicott J. The Burden of Moderate/Severe Premenstrual Syndrome and Premenstrual Dysphoric Disorder in a Cohort of LatinAmerican Women. Science direct journal 2011;14 [7]:593-595.

[5] Kathleen M, Lustyk B, Gerrish W. Premenstrual Syndrome and Premenstrual Dysphoric Disorder: Issues of Quality of Life, Stress and Exercise. Springer Science Business Media 2010;8 [12]:14-20.

[6] Khajehei M. Quality of Life: Definition and Measurement. Europe's Journal of Psychology 2013; 9 [1]: 150-162.

[7] World Health Organization. WHO definition of health. Available from: http://www.who.int/about/definition/en/print.html. [Accessed $14 \backslash 10 \backslash 2014]$.

[8] Marques P, Haag U, Julian F, John E, Soro M. Health-related quality of life impact of a triple combination of olmesartanmedoxomil, amlodipine besylate and hydrochlorotiazide in subjects with hypertension 2015; 13 [24]. DOI 10.1186/s12955-015-0216-6.

[9] Hays R, Sherbourne C, Mazel R. The RAND36- item health Survey 1.0. health Econ 1993;2 [217].

[10] Mustafa R, Masood N, Rizwan N. Study of premenstrual syndrome on quality of life at a University Hospital of Sindh. International Journal of Medicine and Medical Sciences 2013; 3 [3]:383-385.

[11] Lothar A, Minh T, Flionenko A,HOchgraber K. Explorative evaluation of the impact of premenstrual disorders on the daily functioning and quality of life. Berlin center or epidemiology and health researches 2010;11 [5]14-20.

[12] Farrokh-Eslamlou H, Oshnouei S, Heshmatian B, Akbari E.
Premenstrual syndrome and quality of life in Iranian medical students. Sexual \& Reproductive Healthcare 2014;4[9]:198-208.doi: 10.1016/j.srhc.2014.06.009.

[13] Steiner M, Macdougall M, Brown E. The premenstrual symptoms screening tool [PSST] for clinicians. Arch Women Ment Health 2003;6[3]:203-209.

[14] Abdulaziz S, Joel S, Jolaine R. Translation of the RAND 36item health Survey 1.0 [aka SF-36] into Arabic. RAND institution, Santa Monica, N. W.,Washington, DC. 2005-4792.

[15] RAND Corporation. 36-Item Short Form Survey [SF-36] Scoring Instructions available from: http://www.rand.org/health/surveys_tools/mos/36-item-short-f orm/scoring.html [Accessed 22/9/2014].

[16] Delara M,Ghofranipour F, Azadfallah P, Sadat S, Kazemnejad A,Montazeri A. Health related quality of life among adolescents with premenstrual disorders: a cross sectional study. The journal of health and quality of life outcomes 2012;10 [1]:1-8.

[17] Wouters S, Doumen S, Germeijs V, Colpin H, and Verschueren K. Contingencies of self-worth in early adolescence: The antecedent role of perceived parenting. Social Development2013; 22 [2], 242-258. doi:10.1111/sode. 12010 .

[18] Baba A. Issa, Abdullah D. Yussuf, Abdul Waheed O. Olatinwo, Martin Ighodalo. Premenstrual dysphoric disorder among medical students of a Nigerian university. Annals of African Medicine2010;9 [3]:118-122. DOI: 10.4103/1596-3519.68354.

[19] Andrea J, Rapkin, Sharon A Winer. Premenstrual syndrome and premenstrual dysphoric disorder: quality of life and burden of illness. Expert Review of Pharmacoeconomics\& Outcomes Research 2009; 9 [2]157-165.

[20] Indusekhar R, Usman S, O'Brien S. Psychological aspects of premenstrual syndrome. Best Practice \& Research Clinical Obstetrics and Gynecology 2007; 21 [2]:207-220.

[21] Brohi ZP, Haider G, Zehra N, Amna A. Frequency and Impact of premenstrual syndrome on quality of life. Pak J Med Sci 2011;27 [2]:396-400.

[22] Pinar G, Colak M, Oksuz E. Premenstrual Syndrome in Turkish college students and its effects on life quality. Sexual \& Reproductive Healthcare 2011; 2 [10]: 21-27.

[23] Dennerstein L, Lehert PH, Keung L, Ahsan S, Choi D. Asian study of effects of premenstrualsymptoms on activities of daily life. Menopause International 2010; 16 [8]: 146-151. DOI: $10.1258 / \mathrm{mi} .2010 .010035$.

[24] Yang M, Wallenstein G, Hagan M, Guo A, Chang J and Kornstein S. Burden of Premenstrual Dysphoric Disorder on Health-Related Quality of Life. Journal of women's health 2008;17 [1]:10-18. DOI: 10.1089/jwh.0417.

[25] Luisa M,Alcal_a-HerreraV. Age at Menarche, Reactions to Menarche and Attitudes towards Menstruationamong Mexican Adolescent Girls. North American Society for Pediatric and Adolescent Gynecology 2014;14 [6]:102-110.

[26] Sadiq MA, Salih AA. Knowledge and Practice of Adolescent Females about Menstruation in Baghdad. J Gen Pract 2013;2[9]: 138-145. doi:10.4172/2329-9126.1000138. 
[27] Frederick J. The First Taboo: How Menstrual Taboos Reflect and Sustain Women's Internalized Oppression. Available from: http://home.comcast.net/ theennead/bean/menarche.htm. [Acessed at:14/6/2015].

[28] Dube SH, Sharma K. Knowledge, Attitude and Practice Regarding Reproductive Health among Urban and Rural Girls: A Comparative Study. Ethno Med2012;6 [2]: 85-94.

[29] Janet Lee. A Kotex and a Smile": Mothers and Daughters at Menarche. Journal of Family Issues2008; 29 [8]:1325-1347.

[30] Anne M. Teitelman. Adolescent Girls' Perspectives of Family Interactions Related to Menarche and Sexual Health. Qual Health Res. 2004; 14 [10]: 1292-1308.

[31] Gun I, Moller M, Gunnarsson R. Attitudes and feelings towards menstruation and womanhood in girls at menarche. ActaPædiatrica 2006; 9 [5]: 707-714.

[32] Kavita S, Nagaraj CH. Dysmenorrhea and premenstrual syndrome: frequency and effect on daily life activities of adolescent girls in rural areas of Bangalore. International journal of medical signs and public health 2014;13 [10]:102-115.

[33] Florence E, El-Mrrzouk R, Delles H, Nellson O, Alexander E. Premenstrual dystrophic disorder: prevalence and effect 'on nursing student's academic performance and clinical training in Kuwait. Blackwell publishing. Journal of clinical nursing 2011;20 [2]:2915-2923.

[34] Diaa E, Mosallam M, Alyan S,NagelkerkeN. Prevalence and impact of premenstrual syndrome in adolescent schooling girls in United Arab Emirates. ActaObestetriciaetgynacologica 2006;85 [3]:589-598.

[35] Nisar N, Zehra N, Haider G, Munir A, Sohoo N. Frequency, Intensity and Impact of Premenstrual Syndrome in Medical Students. Journal of the College of Physicians and Surgeons Pakistan 2008;18 [8]: 481-484.

[36] Tenkir A,Fisseha N and Ayele B. Premenstrual syndrome: prevalence and effect on academic and social performances in students in Jimma University, Ethiopia. Ethiop.J. health. Dev2002;17 [3]:181-188. 